\title{
Abuso sexual na infância e adolescência femininas: um estudo em um hospital escola
}

\author{
Maria Teresa Aquino Campos Velho*, Deise Silva Cantarelli**, \\ Luciele Cristofari da Silva***, Fernada Gabriel Santos ${ }^{* * *}$
}

RESUMO: Neste artigo, buscou-se conhecer as características sócio-demográficas e o histórico médico de meninas, crianças e adolescentes, vítimas de abuso sexual, atendidas no Hospital Universitário da Universidade Federal de Santa Maria, no período de fevereiro a dezembro de 2009. Como método de análise dos dados utilizou-se a estatística descritiva. A faixa etária prevalente no grupo estudado foi de 10 a 15 anos $(53,3 \%)$, predominaram jovens de cor branca $(80,0 \%)$. A maioria referiu ser estudante $(66,7 \%)$ e oriundas de famílias de baixa renda $(40,0 \%$ sobrevivem com 1 a 2 salários mínimos), cujos pais biológicos eram separados em $66,7 \%$. Constatou-se que a casa da vítima foi o local predominante onde ocorreu 0 abuso (46,7\%), e em $60,0 \%$ das vezes, o fato ocorria durante 0 dia, sendo 0 abusador geralmente um familiar ou alguém conhecido da vítima. 0 padrasto foi citado como agressor em $20,0 \%$ dos casos e outros familiares ou conhecidos figuraram em menores proporções.

Descritores: Violência sexual, Adolescente, Maus-tratos sexuais infantis.

\section{Sexual abuse in female children and adolescents: a study in a school hospital}

ABSTRACT: In this article, we sought to understand girls', children's and adolescents' sociodemographic and medical records, victims of sexual abuse, who were taken care at University Hospital ofSanta Maria-RS from February to December 2009. Descriptive statistics was used as a data analysis method. The most prevalent age group varied from 10 to 15 years (53.3\%), with a predominance of white youngsters $(80.0 \%)$. Most of them reported being students (66.7\%) and from low-income families ( $40.0 \%$ get by on 1 to 2 minimum wages), whose biological parents were separated in $66.7 \%$. It turns out that the victim's home was the predominant site where the abuse took place $(46.7 \%)$, and $60.0 \%$ of the cases happened during the day, once the abuser is usually a family member or someone the victim knows. The stepfather was cited as the aggressor in $20.0 \%$ of cases and other family members or acquaintances appeared in smaller proportions.

Descriptors: Sexual violence, Adolescent, Child sexual abuse.

*Professora Doutora do Departamento de Ginecologia e Obstetrícia da Universidade Federal de Santa Maria (UFSM), Santa Maria, RS, Brasil.

** Médica Ginecologista e Obstétra pelo serviço de Ginecologia e Obstetrícia do Hospital Universitário de Santa Maria (HUSM), Santa Maria, RS, Brasil.

***Médica pela Universidade Federal de Santa Maria (UFSM), Santa Maria, RS, Brasil. 


\section{Introdução}

A violência contra crianças e adolescentes é uma condição que transpõe os séculos, porém a devida atenção a esse fato, no sentido de defesa dos direitos dessas pessoas, teve início no século XX, mais especificamente após a Segunda Guerra Mundial'1.

Esse fenômeno engloba todas as formas de maus tratos físicos e emocionais, abuso sexual, descuido ou negligência, exploração comercial ou de outro tipo, que originem um dano real ou potencial para a saúde da criança, sua sobrevivência, desenvolvimento ou dignidade, no contexto de uma relação de responsabilidade, confiança ou poder ${ }^{2,3}$.

Em 1959, a Organização das Nações Unidas (ONU) elaborou a Declaração Universal dos Direitos da Criança, um conjunto de normativas a respeito do direito da criança à igualdade, proteção, assistência, educação, amor, compreensão e a crescer dentro de um espírito de solidariedade e justiça ${ }^{3}$.

Dispositivos em defesa dessa faixa etária da população surgiram em várias partes do mundo. No Brasil, o Estatuto da Criança e do Adolescente (ECA), elaborado em 1990, regulamenta leis e ações a esse respeito 4 .

A violência sexual, especificamente, ocorre quando a vítima, criança ou adolescente, tem idade e desenvolvimento psicossexual inferior ao do agressor especificado, em geral, em diferença de idade igual ou maior que cinco anos. Tal fato pode expô-la a estímulos sexuais impróprios para a sua idade ou ela pode ser usada para a satisfação sexual do abusador ou de outra pessoa. Estas práticas eróticas e sexuais são impostas às crianças ou aos adolescentes pela violência física, ameaças ou indução de sua vontade. Podem variar desde atos em que não existam contatos físicos (fotografias), mas também aqueles que envolvem o corpo (toques, assédio, voyeurismo, exibicionismo), aos diferentes tipos de atos com contato físico sem penetração peniana (sexo oral, intercurso interfemural) ou com penetração (peniana, digital, com objetos, intercurso genital ou anal). Engloba, ainda, a situação de exploração sexual, visando ao lucro, como a prostituição e a pornografiaa, ${ }^{5,6}$

A violência representa hoje uma das principais causas de morbimortalidade, especialmente entre a população jovem. A violência sexual afeta, principalmente, mulheres jovens (abaixo dos 20 anos) e ocorre geralmente no espaço doméstico, ${ }^{6,7}$. Esta forma de abuso é uma manifestação de disfunção familiar e costuma ser crônica, recorrente e sem violência ${ }^{5}$.

Estima-se que em cada 100 mulheres brasileiras, 15 vivem ou já viveram algum tipo de violência. Comumente o agressor é alguém da família ou próximo a ela. Autores fazem a observação que em $74,8 \%$ dos casos de violência o agressor é próprio marido da vítima e em $12,2 \%$ é o companheiro ${ }^{8}$. A história de abuso sexual, em estudos de prevalência na infância, mostrou ser mais comum entre meninas do que em meninos 9,10 .

Fatores frequentemente citados como associados ao abuso e negligência na infância e adolescência incluem a baixa renda, a escolaridade materna baixa, a etnia não branca, a família composta por muitos indivíduos, a mãe jovem, o pai ou a mãe solteiro/a, a existência de um distúrbio psiquiátrico materno/paterno, a presença de padrasto, entre outros ${ }^{5,11}$.

É descrito que crianças e adolescentes sexualmente abusados podem desenvolver transtornos de ansiedade, sintomas depressivos e agressivos, apresentar problemas quanto ao seu papel e funcionamento sexual, como também no relacionamento com as pessoas no meio em que vivem. Alguns estudos apontam a forte relação entre abuso sexual na infância e adolescência e a ocorrência de depressão na idade adulta ${ }^{12,13}$. 
Ao lado das questões no terreno do emocional, vários problemas de ordem física podem ocorrer. Entre eles, citam-se os traumas que podem ser brandos ou até severos com consequências agudas e/ou crônicas para a vítima: as lacerações vaginais e/ou anais, as doenças sexualmente transmissíveis (condiloma, gonococcia, infecções por clamídia, Aids). A gravidez na adolescência é uma intercorrência não rara em tais situações, que se superpõe ao problema da violência, como mais um agravante impeditivo ao desenvolvimento da adolescente. Envolve, então, outro ser humano - a criança que pode nascer -, que passa então, a fazer parte da cadeia resultante das coações físicas, psíquicas e morais ${ }^{12,14}$.

Se existe um dano corporal, a violência física e/ou sexual podem ser aquelas mais visíveis e mais fáceis de serem identificadas. Todavia, as outras formas de dano, muitas vezes contínuos e recorrentes, podem ir além das marcas físicas pois interferem moral, social e psicologicamente no desenvolvimento das jovens. Desse modo, a violência sexual constitui-se em um problema multifatorial que deve ser abarcado por várias esferas da sociedade que transitam do médico ao jurídico, dentre outros.

A importância crucial desse fenômeno consiste no fato de atingir e afetar um ser humano em formação. Sendo assim, prejudica o indivíduo em todo o seu desenvolvimento biopsicossocial, pois inibe ou impede a expressão de seu viver e de suas plenas potencialidades. A vitimização sexual de crianças e adolescentes envolve, pois, diferentes formas de agressão física, emocional, social e familiar. Tal acontecimento, inexoravelmente, promove agravos indeléveis ao longo de toda a vida da pessoa. Uma atuação pertinente diante da questão do abuso sexual pode contribuir para obstruir e/ou descontinuar os danos causados.

\section{Metodologia}

Este estudo caracterizou-se como uma pesquisa quantitativa, de caráter prospectivo e descritivo, na qual a população estudada constituiu-se de crianças e adolescentes do sexo feminino que foram sexualmente abusadas e que procuraram atendimento no Hospital Universitário de Santa Maria (HUSM) durante o período de fevereiro a dezembro de 2009. Neste período de tempo estipulado pelo projeto, o número de mulheres que compuseram 0 grupo de estudo foi de 15 meninas, ou seja, todas aquelas que compareceram ao HUSM, no período estipulado, buscando auxílio às suas queixas. As conclusões demonstradas neste estudo dizem respeito, portanto, a esse universo de pessoas. Reitera-se que o número de pessoas que procuram os serviços que não são especializados, exclusivamente, para este tipo de atendimento, não são elevados.

Os exames clínicos e laboratoriais e o preenchimento do protocolo foram feitos sob a aquiescência das vítimas e/ou dos responsáveis (quando necessário e oportuno) e após assinatura do termo de consentimento livre e esclarecido.

Os dados aqui analisados referem-se à parte dos achados da pesquisa "Abuso sexual na infância e adolescência femininas: conhecer, compreender e atuar" aprovada pelo Comitê de Ética em Pesquisa da UFSM e abordará os aspectos sócio-demográficos das participantes. A execução do trabalho de campo ficou a cargo de quatro pesquisadores sendo uma delas a coordenadora do projeto, um médico residente do Serviço de Ginecologia e Obstetrícia do HUSM e dois estudantes de medicina, todos submetidos a treinamento prévio

Saúde (Santa Maria), v.38, n.1, p. 71-82, 2012.

Velho, M. T. A. C.; et al. e participação em estudo piloto. 
Foram considerados critérios de inclusão para o estudo ter idade até os vinte anos incompletos, ser do sexo feminino, ter sido abusada sexualmente, e procurado 0 atendimento no HUSM durante o período de fevereiro a dezembro de 2009 e, além disso, a pessoa ou responsável deveriam concordar em participar da pesquisa. Aquelas que não se enquadravam nestes quesitos não fizeram parte do grupo que foi estudado.

Como instrumento de pesquisa foi utilizado um questionário composto por quatro partes: dados referentes à vítima (idade, raça, estado civil, escolaridade, crença religiosa, profissão), ao abuso (tempo para a denúncia, a quem procurou por ajuda, responsável pela denúncia, local e data do evento, tipo de relação, presença ou não de lesão corporal, se o agressor era conhecido ou não da vítima), à família (idade, escolaridade e profissão dos pais, renda familiar, uso de álcool ou drogas, com que a vítima mora). Uma parte do protocolo que constou da anamnese e exame físico ginecológico, que não serão abordados neste artigo.

Ressalta-se que todas as participantes concordaram voluntariamente em tomar parte do estudo e obtiveram a permissão de seus responsáveis legais para responder ao questionário (o exame físico fazia parte necessária de sua consulta ginecológica para confirmação do abuso). A voluntariedade foi assegurada pelos pesquisadores através de consentimento/assentimento livre e esclarecido, obedecendo às normativas para pesquisa com crianças e/ou adolescentes ${ }^{15}$. Foi-lhes assegurado 0 anonimato de sua identidade e de que os dados seriam apresentados em conjunto, sem possibilidade de identificação da pessoa.

Para a análise dos dados, foi utilizada a estatística descritiva das variáveis. As análises foram desenvolvidas com o auxílio do aplicativo computacional SPSS 15.0, pertencente à instituição onde se realizou o estudo.

\section{Resultados}

Foram analisados os questionários respondidos por 15 meninas que procuraram 0 serviço no período estipulado pelo estudo. A média das idades das participantes foi de 10 anos (idade mínima de dois e a máxima de 18 anos).

Observou-se que 12 meninas $(80,0 \%)$ eram brancas e três declararam-se pardas $(20,0 \%)$. A maioria delas disse professar a religião católica $(73,3 \%)$, duas referiram ser mórmon (13,3\%), uma evangélica $(6,7 \%)$ e outra declarou não ter religião $(6,7 \%)$. Com relação à ocupação, dez estudavam $(66,6 \%)$, três relataram não ter nenhuma ocupação $(20,0 \%)$, uma declarou trabalhar em casa $(6,7 \%)$ e uma delas tinha apenas dois anos de idade $(6,7 \%)$, não lhe sendo computada nenhuma ocupação.

Quanto à renda familiar das entrevistadas, a grande maioria delas $(40,0 \%)$ referiu receber de um a dois salários mínimos, enquanto que somente 13,3\% recebiam de quatro a cinco salários mínimos.

Das entrevistadas, $6,7 \%$ não haviam estudado, $20 \%$ delas cursavam da 1a a 4a série do ensino fundamental; 53,3\% estudaram da $5 a$ a $8 a$ série do ensino fundamental e 20,0\% cursavam o ensino médio.

A maioria das vítimas vivia somente com a mãe biológica (40,1\%), enquanto que $20,0 \%$ viviam com os dois genitores biológicos (mãe e pai), duas (13,3\%) viviam somente com o pai 
e outras duas (13,3\%) viviam em "casas-abrigo" que são instituições existentes na cidade, para oferecer acolhida legal para meninas vítimas de violência. As duas restantes $(13,3 \%)$ viviam com outros familiares.

Com relação à situação conjugal de seus pais, a maioria relatou que seus pais biológicos eram separados (66,7\%), enquanto que para $33,3 \%$ das participantes os mesmos eram casados ou viviam em união estável.

No tocante às circunstâncias que envolveram a situação e o momento do abuso sexual, assim como da ocasião do rompimento do segredo, pode-se dizer que, em geral, as jovens recorreram a algum tipo de ajuda de pessoas mais velhas ou seja, $20,0 \%$ delas procuraram os próprios pais; $26,7 \%$ os tios e solicitaram ajuda no mesmo percentual $(6,7 \%)$ respectivamente, ao conselho tutelar, ao médico, à polícia civil, à brigada militar ou a amigos. Em 20,0\% dos casos, as meninas contaram que alguém denunciou o fato de forma anônima às autoridades competentes ou procuraram algum tipo de auxílio por elas.

Quando os entrevistadores perguntaram se alguém mais sabia ou suspeitava do fato de a menina ser vítima de abuso sexual, sete $(46,7 \%)$ disseram que até o momento da revelação, fosse ela mais precoce ou mais tardia (até mais de um ano), ninguém sabia do que Ihes ocorria. Já outras $(26,7 \%)$ afirmaram que alguém da família sabia do acontecido e em $13,3 \%$ disseram que algum vizinho conhecia o fato. As demais participantes (13,3\%) não respondeu a esta questão. O tempo transcorrido entre a denúncia do abuso e/ou 0 rompimento do segredo pode ser observado na Figura 1.

Figura 1 - Período de tempo decorrido, relatado pelas participantes, até a denúncia do abuso sexual. Santa Maria, 2009.

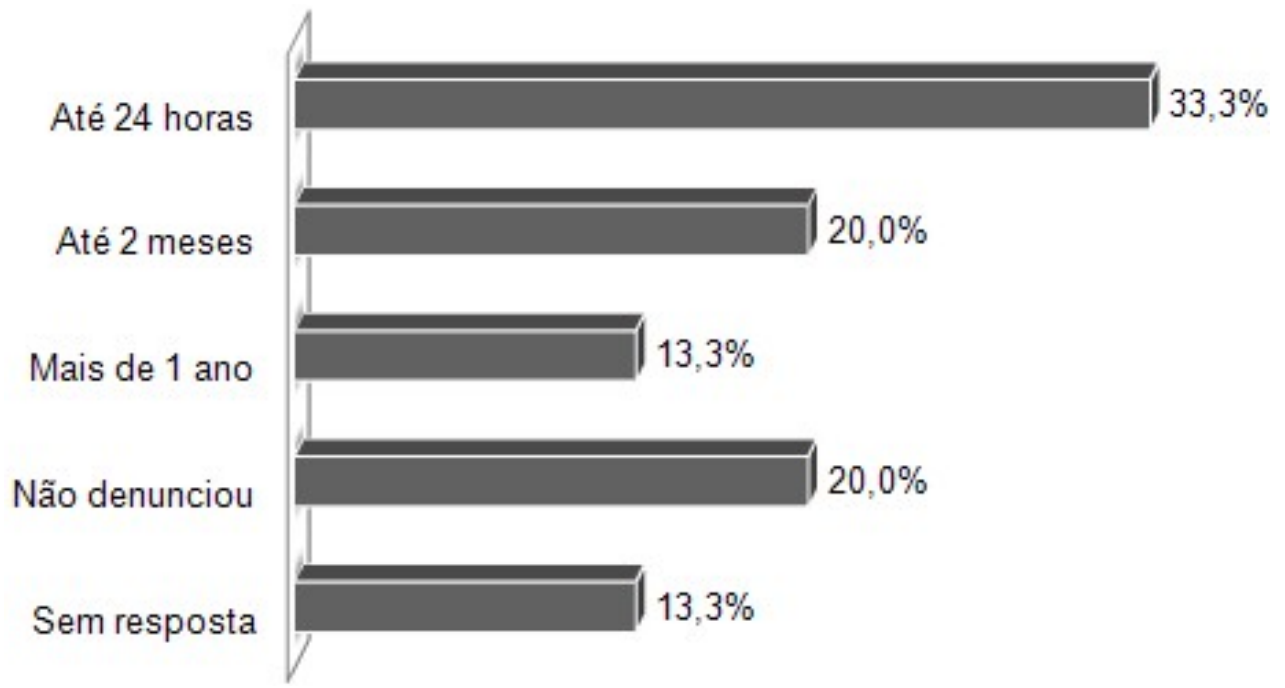

Quando ocorre a situação do abuso sexual, em algum momento, existe um fator que auxilia ou aciona um gatilho que faz preponderar a decisão ou o ímpeto de romper com 0 segredo e, de alguma forma, denunciar o acontecido. Na maior parte dos casos o segredo relacionado ao abuso é arduamente mantido e conservado pelas vítimas, às vezes, por longos anos. Os motivos relacionados pelas entrevistadas do presente trabalho, que as encorajaram a romper o segredo estão explicitados na Figura 2. 
Figura 2 - Descrição, em percentagem, do fator que desencadeou a revelação do abuso sexual. Santa Maria, 2009.

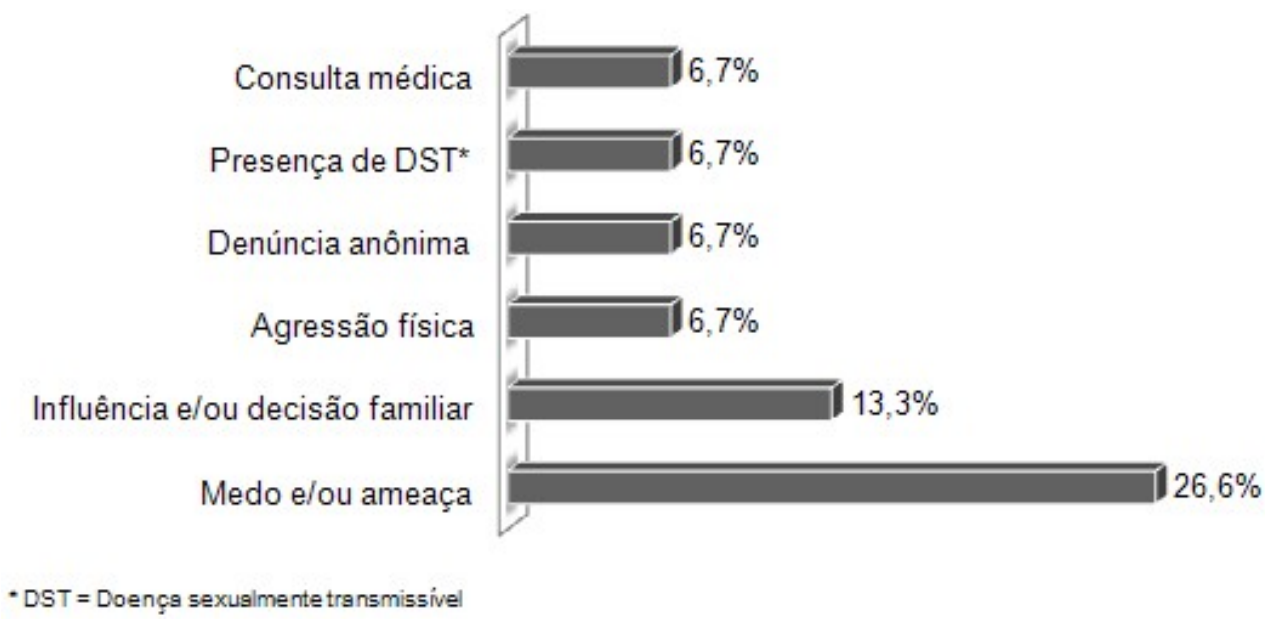

Ao responderem a questão que versava sobre a pessoa havia feito a denúncia até 0 momento do atendimento médico, constatou-se que os próprios pais $(40,0 \%)$ predominaram neste tipo de conduta, seguido pela vítima em $20,0 \%$ dos casos, outros familiares em $13,3 \%$, denúncia anônima em 6,7\% e ausência de denúncia em $20,0 \%$ ou seja, as vítimas procuraram diretamente o hospital e estes notificaram a ocorrência ao Conselho Tutelar.

Quanto aos locais onde os fatos descritos ocorreram, observou-se que a casa da vítima foi, geralmente, onde o abuso sexual $(46,7 \%)$ ocorreu de forma mais frequente. Tal evento ocorreu na casa do próprio abusador em $20,0 \%$ das vezes. Com menor frequência $(6,7 \%)$, 0 abuso sexual ocorreu em outros locais descritos pelas vítimas como: matagal, motel, estação férrea, carro. Uma vítima (6,7\%) não informou o local do abuso sexual.

As violências sexuais contra as meninas que procuraram o serviço de Ginecologia do HUSM ocorreram, na maior parte das vezes, em dias úteis (40,0\%), enquanto que em $26,7 \%$ ocorreram em finais de semana ou feriados. Três jovens $(20,0 \%)$ ignoravam o dia em que aconteceu 0 episódio. Sessenta por cento das vítimas referiram ter sofrido as agressão durante 0 dia (entre sete e dezenove horas) o que se constitui em um dado bastante revelador. As demais meninas não souberam informar com precisão a hora da ocorrência dos abusos.

Com relação ao tipo de violência sexual sofrida e visível ao momento da entrevista, observou-se que sete das jovens $(46,7 \%)$ referiram ter tido relações sexuais completas com penetração vaginal e em $40,0 \%$ das vezes não ocorreu penetração vaginal. Em um caso $(6,7 \%)$ houve penetração anal. Além deste tipo de lesão, em $20,0 \%$ dos casos, foram referidos outros tipos de agressão física, como escoriações, hematomas, queimaduras. Muitas relataram $(57,1 \%)$ que, concomitantemente, às agressões físicas sofridas, a elas se somaram as agressões psíquicas, como as ameaças, por exemplo.

Quando foram investigadas as características do abusador, verificou-se que em grande percentual dos casos ele era um conhecido da vítima (80,0\%). Esta descrição dos abusadores pode ser observada na Figura 3 .

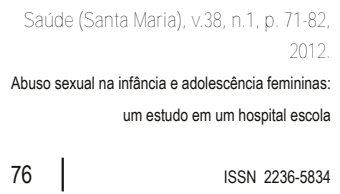


Figura 3 - Identidade e/ou parentesco do agressor das vítimas de abuso sexual. Santa Maria, 2009.

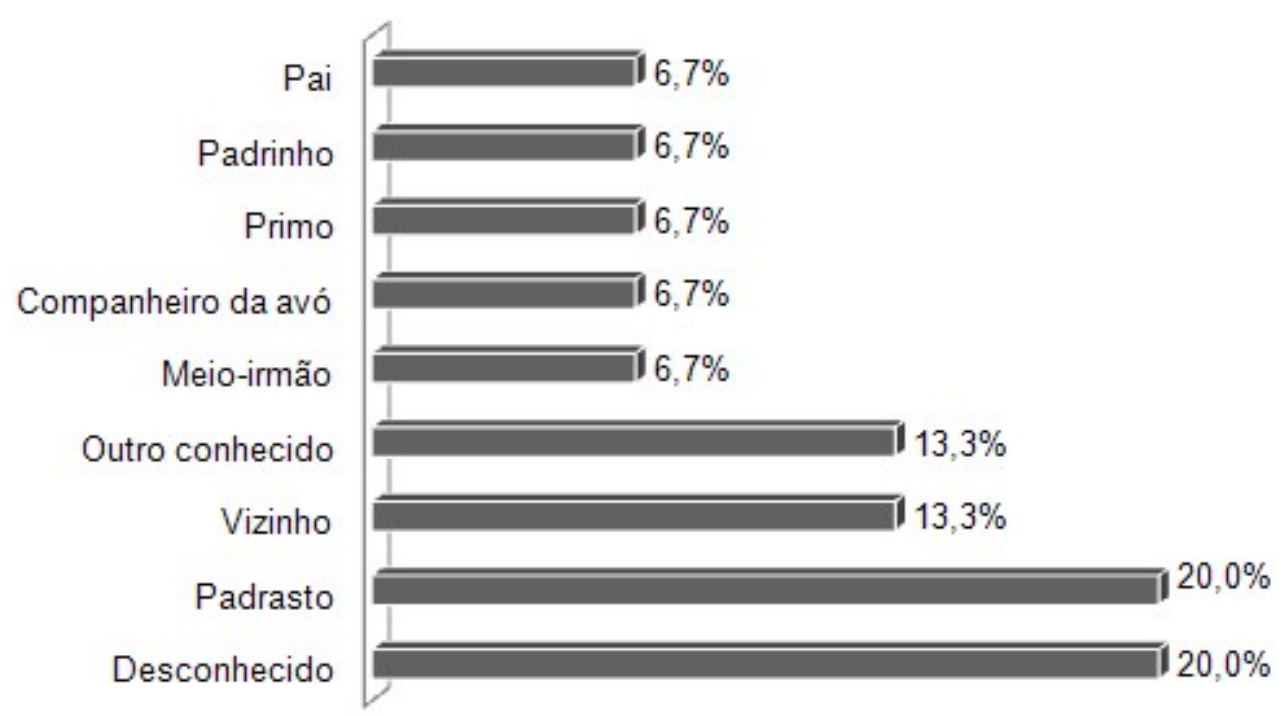

\section{Discussão}

A violência sexual representa um problema importante nas questões de saúde pública, é uma ocorrência de ordem universal e, em princípio, não respeita a classe social onde se insere a pessoa vitimada ou seja, não ocorre apenas nas classes sociais mais baixas. Nestas, especificamente, apenas a descoberta do fato ou o seu relato aparece mais do que nas classes mais favorecidas onde o segredo se mantém de modo mais persistente e durante mais tempo. A dita baixa prevalência de abuso sexual, em muitos países, pode estar vinculada a limitações socioculturais que impedem de modo mais acentuado que ocorra a revelação do segredo. O silêncio a respeito do tema pode ser maior, pois existem impedimentos e dificuldades (sexo como tabu, papel das mulheres na sociedade) para que 0 assunto seja abordado em diversas instâncias, até na mídia ${ }^{16}$.

Esta última, muitas vezes através de campanhas veiculadas por televisão, rádio, jornais e revistas, constituiu-se nos últimos anos, em um poderoso fator impulsionador, ao estimular as vítimas a revelarem o seu segredo. Por trás dessas campanhas grupos de pessoas e estudiosos do tema, auxiliam no modo e nos dizeres da veiculação, fundamentados em pesquisas e bases teóricas consistentes sobre 0 assunto. Têm consciência que tal delito implica em sérios riscos físicos e psíquicos indeléveis para as crianças ou adolescentes neles envolvidos ${ }^{17}$.

No presente trabalho, foram analisados os dados de todas as crianças ou adolescentes que foram abusadas sexualmente e foram atendidas no serviço de ginecologia do hospital escola, no tempo especificado no texto. No entanto, faz-se necessário esclarecer que, como sugerem os marcos teóricos sobre o tema, o abuso sexual aqui considerado, não implicou em levar em conta somente as relações sexuais com penetração vaginal. $O$ assédio, as carícias, os toques, o constrangimento, a exploração física ou visual (mídia, internet) também fizeram parte do contexto considerado ${ }^{18,19}$.

Saúde (Santa Maria), v.38, n.1, p. 71-82, 2012.

Velho, M. T. A. C.; et al.

ISSN 2236-5843 meninos chegam à idade adulta tendo sofrido algum tipo de violência sexual e que, não mais que $10 \%$ das violências praticadas conseguem ser reveladas. Este dado demonstra a 
dificuldade da ruptura do segredo, que é o grande perpetuador do problema, e aponta 0 possível motivo pelo qual ainda é pouca a procura dessas pessoas, pelos serviços de saúde ou jurídicos, para auxílio ou resolução das consequências de um abuso ou, mais dificilmente, a sua prevenção $(5,7)$. Talvez, por isso, ao longo de quase um ano, apenas quinze meninas foram atendidas por essa queixa no HUSM. Este conjunto de fatores assegura a impunidade que permeia a situação e demonstra que, no geral, os adultos apresentam uma grande falta de preparo para ouvir e conduzir este tipo de revelação seja na família, na escola e até mesmo nos setores da saúde e da justiça. Autores afirmam, que muitos adultos que atuam em qualquer área profissional, inclusive os da saúde, costumam desqualificar ou negar os relatos das crianças. Segundo a autora, este ponto cego dos profissionais é lamentável, pois os estudos indicam que o modo de reação dos adultos diante desta revelação, se não for bem conduzida, é um dos principais fatores que mantém o então, somatório de traumas presentes e/ou futuros ${ }^{17,18}$.

Observou-se que, no presente estudo, os abusos ocorreram principalmente em meninas com a idade de dez ou mais anos (foi descrita uma média etária de dez anos mas o relato de um abuso sexual aos dois anos de idade em uma menina, desviou a média para baixo). Os artigos, no geral, divergem quanto à faixa etária de maior prevalência da violência sexual, sendo que enquanto alguns encontraram resultados semelhantes ao desse estudo ${ }^{18}$, outros apontaram resultados de idades de ocorrência entre oito e doze anos ${ }^{20}$ e faixas etárias maiores do que dez anos ${ }^{19}$. Em Porto Alegre (RS), em um total de cinquenta casos analisados, houve apenas um caso de uma menina com idade de dois anos ${ }^{18}$. As consequências psicológicas da violência sexual tendem a se tornar mais graves após os sete anos, idade que a criança passa a compreender os valores morais e sociais relacionados ao sexo21.

A maior parte das meninas entrevistadas declarou ser de cor branca e a renda familiar, em média, foi de um a dois salários mínimos. Estes dados são compatíveis com os encontrados por outro estudo corroborando a ocorrência do abuso sexual - pelo menos daquele que vem à tona e torna-se público -, nas classes menos favorecidas ${ }^{18}$.

Um percentual expressivo das meninas tinha por ocupação o estudo, sendo que a maior parte dessas estava entre a quinta e oitava série do primeiro grau. Apenas uma jovem cursava o terceiro grau. A literatura não é muito específica ao referir a escolaridade das vítimas; descreve mais, em geral, sobre a escolaridade da família. É referido que 0 abuso sexual tende a ocorrer mais frequentemente em famílias de baixa renda, com baixa escolaridade - principalmente a materna -, sendo a família, no mais das vezes, numerosa. A mãe em geral é jovem e os pais são solteiros ou separados ${ }^{5,11}$. No grupo analisado por esta pesquisa, em $66,6 \%$ dos casos, a família da qual se originava a vítima tinha os pais biológicos separados.

Ao se levar em conta a configuração familiar das vítimas na época em que foi realizada a pesquisa, a maior parte delas, vivia com a sua mãe ou com os pais biológicos. A particularidade, no presente estudo, é o fato de duas das meninas viverem em casas-abrigo, que são instituições que as acolhem para separá-las do agressor. A existência destas instituições, uma das possíveis respostas do Estado ao problema é fundamental pois, a manutenção da vítima junto ao agressor após a descoberta do fato, torna essa convivência difícil e/ ou impossível.

Quando as jovens foram estimuladas a descrever as circunstâncias que envolveram a situação do abuso sexual - quando do momento do abuso ou do momento do rompimento do 
segredo -, pode-se dizer que a maioria das participantes contou ter procurado algum tipo de ajuda através de alguma pessoa ou instituição (Conselho Tutelar e polícia) para realizar a revelação. Estudo na cidade de Porto Alegre ressalta que a pessoa a quem a vítima recorreu foi, preferencialmente, a própria mãe em $42 \%$ dos casos, os irmãos em $10 \%$ e os tios em $4 \%$ das vezes ${ }^{18}$.

O rompimento do segredo pela vítima é um fato bastante complexo. A literatura é unânime em afirmar que, no geral, o agressor é seu conhecido ou pessoa muito próxima em seus vínculos afetivos, o que acarreta uma enorme dificuldade da menina em revelar o fato $6,7,18$. Neste estudo, o abusador em $20,0 \%$ dos casos foi o padrasto, um conhecido ou um vizinho em igual proporção, havendo também pessoas como o próprio pai (um caso), o padrinho, o primo, um meio-irmão e o companheiro da avó. Pôde-se certificar então, as afirmações citadas pela literatura, as quais enfatizam que quanto ao perfil do perpetrador do abuso sexual, em geral, a vítima o vincula a uma figura paterna ${ }^{17}$. 0 pai já foi descrito como 0 principal agressor em $40 \%{ }^{18}$ ou até mesmo em $68,6 \%$ dos casos, enquanto que o padrasto representou $29,8 \%{ }^{17}$.

O trauma causado pelo abuso constante ou ocasional na criança e/ou adolescente e suas consequências e a dificuldade que ela tem em revelar o fato centram-se na defesa dissociativa, ou seja, a criança tem a tendência a idealizar o abusador, por ser ele um conhecido, e assim, degrada a imagem do próprio self17. Há nessa situação, um desafio daquilo que a criança pode compreender como afetividade segura e sadia e isso ameaça a sua sensação básica de segurança com relação ao mundo. Podem se criar experiências muito distorcidas, carregadas de afetividade que continuam a viver não integradas no sobrevivente adulto.

Na ocorrência do abuso sexual constante ou não, em algum momento e por algum motivo, muitas meninas acabam revelando o segredo, até então, completamente reprimido por muito tempo. Tais repressões ocorrem, pois as meninas são enganadas, ameaçadas física ou psiquicamente pelo abusador, sofrendo diuturnamente com o sério conflito. Observou-se, nesta pesquisa, que o medo e/ou as ameaças do agressor foram o gatilho para o rompimento do silêncio, como também demonstrou outra pesquisadora em seu trabalho no $\mathrm{RS}^{18}$.

Nesta investigação, também foi questionado às meninas sobre os locais onde aconteciam as situações de abuso sexual. A própria casa da vítima foi o local prevalente, sendo descritos também outros locais como a casa do abusador. É oportuno salientar que 0 abuso transcorreu, na maior parte das vezes, durante o dia, entre as sete da manhã e às 19 horas. Estes horários coincidem, em geral, com o horário de trabalho das mães das meninas e é aquele que 0 abusador utiliza para atuar. Em estudo que investigou a violência sexual contra mulheres adultas na cidade de Curitiba, observou-se que na maior parte das vezes a vítima era abordada nas ruas e que, muitas vezes, o fato acontecia na própria casa ${ }^{22}$, enquanto que em outros que investigaram apenas crianças e adolescentes, também se constatou que a residência da própria família representou o local mais utilizado para a ocorrência da agressão $0^{18,23}$.

O reconhecimento dos sinais de maus-tratos físicos, psíquicos e sexuais em crianças e adolescentes passa a ser imperativo e, assim sendo, a equipe de saúde, e como parte dessa, os/as médicos/as, necessitam estar atentos e distinguir o que pode ser um sinal ou sintoma

Saúde (Santa Maria), v.38, n.1, p. 71-82, 2012. Velho, M. T. A. C.; et al. 
de um abuso sexual. Desta forma, atentos e preparados para trabalhar com a demanda, podem fazer parte do conjunto de pessoas que precisa abordar o problema de forma adequada e assim sendo, auxiliar no manejo e tentar aprimorar as circunstâncias dolorosas pelas quais passam as vítimas dessa séria dificuldade.

\section{Considerações finais}

A exploração sexual de crianças e adolescentes é uma violação fundamental dos seus direitos. Prevenir ou diminuir os danos futuros, de toda a ordem, ocasionados por fatos tão graves e sofridos são prerrogativas de muitos profissionais que não podem ser negligenciadas. A luta precisa caminhar de forma compartilhada, ao lado das vítimas, na tentativa de diminuir seu sofrimento e evocar elos de esperança. Só assim serão quebradas as barreiras dos silêncios e dos segredos que ainda são as correntes perpetuadoras da agressão. Presta-se, deste modo, auxilio à punição e um maior e mais esclarecido comprometimento de todas as pessoas envolvidos na prevenção e cuidados em relação ao abuso sexual.

\section{Referências bibliográficas}

1. Gomes ILV, Caetano R, Jorge MSB. The rigths of the child in family and in society: cartography of laws and resolutions. Rev. bras. enferm. 2008;1(61): 61-5.

2. Oliveira RR. Autonomia e vulnerabilidade: A violência na vida dos adolescentes. In: Bioética - Estudos e Reflexões 2. Londrina: Editora UEL, 2001.

3. República Federativa do Brasil. Estatuto da Criança e do Adolescente. LEI № 8.069, de 13 de Julho de 1990. Acesso em 04 set 2011. Disponivel em <http://portal.saude.gov.br/portal/arquivos/pdf/L8069.pdf>.

4. World Health Organization. Report of the Consultation on Child Abuse Prevention. Geneva: World Health Organization; 1999.

5. Pires ALD, Miyazaki MCOS. Maus-tratos contra crianças e adolescentes: revisão da literatura para profissionais da saúd. Arq Ciênc Saúde, 2005;12(1):42-9.

6. Habigzang LF, Azevedo GA, Koller SH, Machado PX. Fatores de Risco e de Proteção na Rede de Atendimento a Crianças e Adolescentes Vítimas de Violência Sexual. Psicologia: Reflexão e Crítica, 2006;19(3):379-86.

7. Taquette SR. Violência contra a mulher adolescente-jovem. Rio de Janeiro: EdUERJ, 2007. 208p.

8. DATASENADO. Secretaria de Pesquisa e Opinião Pública - Senado Federal. Brasília, 2007.

9. Lundqvist G, Hansson K, Svedin CG. The influence of childhood sexual abuse factors on women's health. Nord J Psychiatry, 2004; 58(5):395-401.

Saúde (Santa Maria), v.38, n.1, p. 71-82,

2012.

Abuso sexual na infância e adolescência femininas: um estudo em um hospital escola

80 ISSN 2236-5834
10. Brito AM, et al. Violência doméstica contra crianças e adolescentes: estudo de um programa de intervenção. Ciência \& Saúde Coletiva, 2005; 10(1):143-9.

11. Nygren P, Nelson HD, Klein J. Screening Children for Family Violence: A Review of the Evidence for US Preventive Services Task Force. Ann Fam Méd, 2004; 2(2):161-9.

12. Casique LC, Furegato ARF. Violência contra mulheres: reflexões teóricas. Rev. Latino-Am. Enfermagem, 
2006; 6(14): 950-6.

13. Assis $S G$, et al. Situação de crianças e adolescentes brasileiros em relação à saúde mental e à violência. Ciência \& Saúde Coletiva, 2009; 14(2):349-61.

14. Campos Velho MT. Gestação na adolescência: um marco na construção de vida do ser - mulher. Floranópolis 2003. 375f. Tese (Doutorado em Enfermagem). Universidade Federal de Santa Catarina.

15. Conselho Nacional de Saúde.Diretrizes e Normas Regulamentadoras de Pesquisas Envolvendo Seres Humanos. Resolução 196/96. Acesso em 04 set 2011. Disponível em : http://conselho.saude.gov.br/index.htm

16. Forjuoh SN, Zwi AB. Violence among children and adolescents. Pediatr Clin North Am, 1998; 45(2)41526.

17. Mees LA. Abuso Sexual - Trauma Infantil e Fantasias Femininas. Porto Alegre: Artes e Ofícios, 2001.

18. Braun, S. A violência sexual infantil na família: do silêncio à revelação do segredo. Porto Alegre: AGE, 2002. 102p.

19. Polanczyk GV, Zavaschi ML, Benetti RZ, Gammerman PW. Violência sexual e sua prevalência em adolescentes de Porto Alegre, Brasil. Rev. Saúde Pública. 2003; 37(1):8-14.

20. Ramos NV; Socal E, Eidelwein K. Pesquisa e diagnóstico sobre crianças e adolescentes em situação de risco pessoal e social em Santa Maria/RS: construindo cidadania. Santa Maria: Editora Palloti, 2003.

21. Lundqvist $G$, Hansson $K$, Svedin CG. The influence of childhood sexual abuse factors on women's health. Nord J Psychiatry, 2004; 58(5):395-401.

22. Jarek G. Corporeidades Vítimas de Violência Sexual. Curitiba 2003. Monografia (Trabalho de Conclusão do Curso de Enfermagem). Universidade Federal do Paraná

23. Habigzang LF, Azevedo GA, Koller SH, Machado PX. Abuso sexual infantil e dinâmica familiar: Aspectos observados em processos jurídicos. Psicologia teoria e Pesquisa, 2005; 21(03):341-348.

\section{Maria Teresa Aquino Campos Velho}

Endereço para correspondência - Departamento de Ginecologia e Obstetrícia, Sala 1333, CCS -

Campus UFSM. 97105-900

Email: mtcamposvelho@gmail.com

Currículo lattes: http://lattes.cnpq.br/3242426873145535

Recebido em 01 de outubro de 2011.

Aprovado em 27 de março de 2012. 
Saúde (Santa Maria), v.38, n.1, p. 71-82,

2012.

Abuso sexual na infância e adolescência femininas:

82 | ISSN 2236-5834 